\title{
Pediatric Sepsis: Markers, Mechanisms, and Management
}

\author{
Derek S. Wheeler*
}

Division of Critical Care Medicine, Cincinnati Children's Hospital Medical Center, The Kindervelt Laboratory for
Critical Care Medicine Research, Cincinnati Children's Research Foundation, Clinical Pediatrics, University of
Cincinnati College of Medicine, USA

Abstract: Sepsis is a significant health problem in both critically ill children and adults. While the mortality rate from sepsis is much lower in children, sepsis is directly responsible for over 4,000 childhood deaths per year in the United States alone. At face value, this number suggests that more children die per year in the United States from sepsis as the primary cause than from cancer. Unfortunately, there are few studies on the epidemiology, pathophysiology, and management of sepsis in children. Moreover, extrapolation of adult data to critically ill children is probably not appropriate due to several key developmental differences in the host response to infection and response to therapy. Therefore, additional studies targeting sepsis in the pediatric population are urgently required.

\section{INTRODUCTION}

Sir William Osler once stated that to know syphilis is to know medicine. Many years later, Zimmerman appropriately followed with the statement that to know sepsis is to know critical care medicine [1]. The early recognition, diagnosis, and management of critically ill patients with sepsis truly define the essence or sine qua non of the field of critical care medicine. Unfortunately, while sepsis defines our specialty, an exact, all-encompassing definition of the sepsis syndrome has been difficult to establish. Sepsis suffers from an identity crisis of sorts. For example, the lay public has very little knowledge of sepsis, especially compared to more commonly recognized causes of death, such as acute myocardial infarction, stroke, and cancer [2]. Health care workers are not much better. A recent international survey of over 1,058 physicians from a wide variety of disciplines, including critical care medicine, found that nearly two-thirds believed that a common definition for sepsis was lacking [3]. Part of the issue is that sepsis is not even really a disease in the strictest sense of the term, but rather a syndrome. The Merriam-Webster dictionary defines syndrome as a group of signs and symptoms that occur together and characterize a particular abnormality or condition. There are no specialized blood tests that can be used to diagnose sepsis with anything close to $100 \%$ certainty. Instead, sepsis remains primarily a clinical diagnosis based upon the identification of a constellation of several, fairly consistent clinical signs and symptoms that occur in association with an infection or other inciting event, e.g. trauma, pancreatitis, or burns. Based on this concept, Roger Bone initially coined the term sepsis syndrome in 1989 [4], and shortly thereafter, an international panel of experts from the Society of Critical Care Medicine (SCCM) and the American College of Chest Physicians (ACCP) proposed the now familiar consensus

*Address correspondence to this author at the Division of Critical Care Medicine, Cincinnati Children's Hospital Medical Center, 3333 Burnet Avenue, Cincinnati, OH 45229-3039, USA; Tel: 513 636-4259;

Fax: 513 636-4267; E-mail: Derek.wheeler@cchmc.org definitions for the systemic inflammatory response syndrome (SIRS), sepsis, severe sepsis, and septic shock (Table 1) [5]. These definitions have been subsequently modified for use in critically ill children with sepsis (Table 2) [6].

\section{CHILDREN ARE NOT SMALL ADULTS}

Why is an entire supplement dedicated to "Pediatric Sepsis" even necessary? The medical literature is replete with articles reviewing the pathophysiology of sepsis at the molecular, cellular, tissue, organ, and whole-organism levels. In addition, there have been entire volumes dedicated to the topic of sepsis. Are there any important differences between pediatric and adult sepsis that merit further discussion? The phrase children are not small adults is wellknown to every pediatrician and certainly applies to critically ill patients with sepsis as well. In fact, there are several key developmental differences in the host response to infection and therapy that clearly delineate pediatric sepsis as a separate, albeit related, entity from adult sepsis. As a result, extrapolation of adult data to critically ill children with sepsis may not always be appropriate. One notable example is the vastly different results between two recently conducted multicenter, randomized, controlled trials of activated protein $\mathrm{C}$ in the management of sepsis. In the adult study (PROWESS), treatment with activated protein $\mathrm{C}$ was associated with an absolute reduction in the risk of death of 6.1 percent $(\mathrm{P}=0.005)$ [7]. Conversely, the pediatric study (RESOLVE) was stopped early for lack of therapeutic effect at the first planned interim analysis [8].

\section{A GROWING PUBLIC HEALTH CRISIS?}

According to the National Center for Health Statistics and the Centers for Disease Control and Prevention, sepsis was the $10^{\text {th }}$ leading cause of death overall in 2004 [9]. In fact, annual deaths from sepsis in both children and adults far surpass the number of deaths from acute myocardial infarction (AMI), stroke, or cancer [10]. The cost of sepsis, in terms of annual health care expenditures, approaches close to $\$ 17$ billion and $€ 6$ billion every year in the U.S. and Europe, respectively $[10,11,14]$. These numbers are likely 
Table 1. American College of Physicians (ACCP)/Society of Critical Care Medicine (SCCM) Consensus Definitions for SIRS, Infection, Sepsis, Severe Sepsis, and Septic Shock

\section{Systemic Inflammatory Response Syndrome (SIRS)}

The presence of at least two of the following four criteria, one of which must be abnormal temperature or leukocyte count:

- Core temperature $>38^{\circ} \mathrm{C}$ or $<36^{\circ} \mathrm{C}$ (by rectal, bladder, oral or central catheter probe)

- Tachycardia, defined as heart rate $>90 / \mathrm{min}$

- Tachypnea, defined as respiratory rate $>20 / \mathrm{min}$ or $\mathrm{PaCO} 2<32 \mathrm{~mm} \mathrm{Hg}$

- White blood cell count $>12,000$ cells $/ \mu \mathrm{L}$ or $<4,000$ cells $/ \mu \mathrm{L}$

\section{Infection}

A suspected or proven (i.e. by positive culture, tissue stain, polymerase chain reaction, etc) infection caused by any pathogen OR a clinical syndrome associated with a high probability of infection (e.g. presence of white blood cells in a normally sterile body fluid, chest radiograph consistent with pneumonia, petechial or purpuric rash, etc)

$\underline{\text { Sepsis }}$

SIRS + Infection

\section{Severe Sepsis (Sepsis with Organ Dysfunction)}

Sepsis plus either cardiovascular dysfunction or acute respiratory distress syndrome (ARDS) OR two or more other organ dysfunctions

\section{Septic Shock}

Severe Sepsis with arterial hypotension defined by a systolic blood pressure below $90 \mathrm{~mm} \mathrm{Hg}$, mean arterial pressure (MAP) $<60 \mathrm{~mm} \mathrm{Hg}$, or a reduction in systolic blood pressure $>40 \mathrm{~mm} \mathrm{Hg}$ from baseline, despite adequate volume resuscitation and in the absence of other causes for hypotension.

Adapted from [5].

\section{Table 2. Consensus Definitions for Pediatric SIRS, Infection, Sepsis, Severe Sepsis, and Septic Shock}

\section{Systemic Inflammatory Response Syndrome (SIRS)}

The presence of at least two of the following four criteria, one of which must be abnormal temperature or leukocyte count:

- Core temperature $>38.5^{\circ} \mathrm{C}$ or $<36^{\circ} \mathrm{C}$ (by rectal, bladder, oral or central catheter probe)

- Tachycardia, defined as mean heart rate $>2$ SD for age (in the absence pain, fever, drug therapy, etc) or otherwise persistent elevation over a 0.5-4 hour time period OR for children $<1$ year of age: Bradycardia, defined as mean heart rate $<10^{\text {th }}$ percentile for age (in the absence of drug therapy or presence of congenital heart disease) or otherwise persistent depression over a 0.5 hour time period

- Mean respiratory rate $>2$ SD above normal for age or mechanical ventilation (not for underlying neuromuscular disease or receipt of general anesthesia)

- Leukocyte count elevated or depressed for age (not due to chemotherapy-induced leucopenia) or $>10 \%$ immature neutrophils

\section{$\underline{\text { Infection }}$}

A suspected or proven (i.e. by positive culture, tissue stain, polymerase chain reaction, etc) infection caused by any pathogen OR a clinical syndrome associated with a high probability of infection (e.g. presence of white blood cells in a normally sterile body fluid, chest radiograph consistent with pneumonia, petechial or purpuric rash, etc)

$\underline{\text { Sepsis }}$

SIRS + Infection

\section{$\underline{\text { Severe Sepsis }}$}

Sepsis plus either cardiovascular dysfunction or acute respiratory distress syndrome (ARDS) OR two or more other organ dysfunctions (see Table 2)

\section{Septic Shock}

Sepsis and cardiovascular organ dysfunction

Adapted from [6].

to get worse. Recent estimates suggest that there are between 77 to 240 new cases of sepsis per 100,000 population each year $[11,12]$. The incidence of sepsis is expected to further increase by $1.5 \%$ every year, resulting in an additional 1 million cases per year by 2020 [10, 11, 13].

Just as important, and perhaps more relevant to the present discussion is the fact that sepsis accounts for 
significant morbidity and mortality in the pediatric age group as well. Sepsis is the most common cause of death in infants and children worldwide [14]. Unfortunately, there are comparatively few studies on the epidemiology of sepsis in children. Proulx and colleagues [15] analyzed the incidence and outcome of sepsis using the aforementioned pediatric consensus definitions in a single tertiary care children's hospital. Out of 1,058 admissions analyzed over a one-year period, $82 \%$ of children admitted to the pediatric intensive care unit (PICU) met criteria for SIRS, while $23 \%$ had sepsis, $4 \%$ had severe sepsis, and $2 \%$ had septic shock. The overall mortality rate for this population was $6 \%$, with the majority of deaths occurring in children with multiple organ dysfunction syndrome (MODS). These results were further corroborated by Watson and colleagues in the largest epidemiologic study of pediatric sepsis reported to date. In this study, sepsis accounted for nearly 4,500 deaths and close to $\$ 2$ billion per year in healthcare expenditures in the U.S. alone [16]. These statistics do not take into account the additional hidden costs attributed to the loss of productivity related to years of life lost for critically ill children who succumb to sepsis.

These sobering statistics suggest that pediatric sepsis is a growing public health problem that is reaching crisis proportions. At face value, more children die from sepsis every year in the U.S. than from cancer. Unfortunately, research funding specifically targeted towards pediatric sepsis is substantially lower than that for pediatric cancer. Additional research funding should be targeted at decreasing the morbidity and mortality from sepsis in children worldwide. Similarly, there is a growing need for educating the public on the dangers of sepsis, particularly in children. Finally, more studies on the epidemiology, pathophysiology, and treatment of pediatric sepsis are desperately required.

\section{ACKNOWLEDGEMENT}

Supported by the National Institutes of Health, 5KO8GM077432 and 1R03HD058246

\section{REFERENCES}

[1] Zimmerman JJ, Ed. Sepsis/septic shock. 2nd ed. St. Louis: Mosby 1998.

[2] Rubulotta FM, Ramsay G, Parker MM, Dellinger RP, Levy MM, Poeze M. An international survey: Public awareness and perception of sepsis. Crit Care Med 2009; 37: 167-70.

[3] Poeze M, Ramsay G, Gerlach H, Rubulotta FM, Levy MM. An international sepsis survey: A study of doctor's knowledge and perception about sepsis. Crit Care 2004; 8: R409-R13.

[4] Bone RC, Fisher CJ, Clemmer TP, Slotman GJ, Balk RA. Sepsis syndrome: a valid clinical entity. Crit Care Med 1989; 17: 389-93.

[5] ACCP, SCCM. Definitions for sepsis and organ failure and guidelines for the use of innovative therapies in sepsis. Crit Care Med 1992; 20: 864-74

[6] Goldstein B, Giroir B, Randolph A. International pediatric sepsis consensus conference: definitions for sepsis and organ dysfunction in pediatrics. Pediatr Crit Care Med 2005; 6: 2-8.

[7] Bernard GR, Vincent JL, Laterre PF, et al. Efficacy and safety of recombinant human activated protein $\mathrm{C}$ for severe sepsis. N Engl J Med 2001; 344: 699-709.

[8] Nadel S, Goldstein B, Williams MD, et al. Drotrecogin alfa (activated) in children with severe sepsis: a multicentre phase III randomised controlled trial. Lancet 2007; 369: 836-43.

[9] Heron M. Deaths: Leading causes for 2004. Natl Vital Stat Rep 2007; 56: 1-95.

[10] Angus DC, Linde-Zwirble WT, Lidicker J, Clermont G, Carcillo J, Pinsky MR. Epidemiology of severe sepsis in the United States: Analysis of incidence, outcome, and associated costs of care. Crit Care Med 2001; 29: 1303-10.

[11] Martin GS, Mannino DM, Eaton S, Moss M. The epidemiology of sepsis in the United States from 1979 through 2000. N Engl J Med 2003; 348: 1546-54.

[12] Finfer S, Bellomo R, Lipman J, French C, Dobb G, Myburgh J. Adult population incidence of severe sepsis in Australian and New Zealand Intensive Care Units. Intens Care Med 2004; 30: 589-96.

[13] Dombrovskiy VY, Martin AA, Sunderram J, Paz HL. Rapid increase in hospitalization and mortality rates for severe sepsis in the United States: a trend analysis from 1993 to 2003. Crit Care Med 2007; 35: 1244-50.

[14] Organization TWHR. The World Health Report: Fighting Disease, Fostering Development. Geneva: World Health Organization 1996.

[15] Proulx F, Fayon M, Farrell CA. Epidemiology of sepsis and multiple organ dysfunction syndrome in children. Chest 1996; 109: 1033-7.

[16] Watson RS, Carcillo JA, Linde-Zwirble WT, Clermont G, Lidicker $\mathrm{J}$, Angus DC. The epidemiology of severe sepsis in children in the United States. Am J Respir Crit Care Med 2003; 167: 695-701.

(c) Derek S. Wheeler; Licensee Bentham Open.

This is an open access article licensed under the terms of the Creative Commons Attribution Non-Commercial License (http://creativecommons.org/licenses/by-nc/3.0/) which permits unrestricted, non-commercial use, distribution and reproduction in any medium, provided the work is properly cited. 